\title{
UMA COMPARAÇÃO ENTRE ESTRATÉGIAS DE ENSINO DA QUÍMICA NA EDUCAÇÃO SUPERIOR
}

\author{
Maria Inês Pinto Bogisch* \\ Paulo Roberto Alcantara**
}

\section{Resumo}

Numa abordagem prática e contextualizada, o presente trabalho analisou quatro procedimentos pedagógicos: a) aula expositiva dialogada com apresentação de vídeo e discussão; b) aula expositiva dialogada com prática laboratorial e discussão; c) aula expositiva dialogada e d) projeto de pesquisa de campo, apresentado em seminário. Durante a implementação dos procedimentos, utilizou-se um ambiente de Aprendizagem Colaborativa via Internet, com 0 intuito de incrementar a motivação dos estudantes e obter uma aprendizagem satisfatória. $\mathrm{O}$ projeto de pesquisa de campo, apresentado em seminário, foi o procedimento pedagógico que mais aumentou a motivação e a aprendizagem. A prática laboratorial fez boa intermediação entre o cotidiano e a Química, enquanto a aula expositiva dialogada foi considerada um meio de obter conhecimentos novos e aprofundar conteúdos.

Palavras-chave: Química; Procedimentos Pedagógicos; Aprendizagem; Seminário; Conhecimento.

\section{Abstract}

In a contextual and practical approach, the present work analyzed four pedagogical procedures: a) dialogued lecture with video presentation and discussion; b) dialogued lecture with laboratorial practice and discussion; c) dialogued lecture; and d) field research project, presented in a seminar. During the procedural implementation, a collaborative learning environment via Internet, was used to increase the students' motivation and to obtain a satisfactory apprenticeship. The field research project, presented in a seminar, was the pedagogical procedure that most increased the motivation and the learning. While the laboratorial practice made good connection between the daily life and chemistry, the dialogued lecture was considered as means of getting new knowledge and to deepen contents.

Keywords: Chemistry; Pedagogical Procedures; Leaming; Seminar; Knowled

* Mestre em Educação.

Email: mbogisch@rla01.pucpr.br

** Ph.D. em Educação

Email: alcantpr@rla13.pucpr.br 


\section{Introdução}

Ao longo dos anos de docência na Educação Superior, tem-se verificado uma grande dificuldade de aliar a visão macroscópica (observações vistas a olho nu dos fenômenos químicos) com a explicação dos fenômenos químicos por meio de uma visão microscópica.

Além disso, em particular, percebe-se uma visão estereotipada da química no curso de Engenharia Elétrica - Telecomunicações na PUCPR, como em outras instituições de ensino superior, havendo constantes reclamações dos alunos em relação às aulas expositivas dialogadas (teóricas), julgando-as cansativas e desnecessárias. Os discentes somente se interessavam por parte das aulas práticas, principalmente aulas relacionadas mais diretamente com 0 curso.

Após dez anos atuando no curso de Engenharia Elétrica-Telecomunicações, encontrando alunos com dificuldades de relacionar o conteúdo da Química com a área de Telecomunicações, apresentando resistência pelo fato de a Química estar na sua grade cumicular, além de não obter um bom nível de motivação, optou-se por reestruturar todo o conteúdo deste programa de aprendizagem. Preferiu-se, então, o ensino contextualizado, usando quatro procedimentos pedagógicos diferentes. Buscava-se, assim, resgatar um ambiente receptivo às aulas de Química, que pudesse aumentar a motivação dos alunos e gerar uma aprendizagem significativa.

\subsection{Metodologia do Ensino}

As idéias arraigadas ao tradicional devem ser modificadas e a Química necessita ser trabalhada de forma criativa, mudando uma realidade de receios para uma realidade de interesse pela pesquisa, pelo conhecimento e aplicabilidade da mesma.

Lévy (1996, p. 7) afirma: "Novas maneiras de pensar e de conviver estão sendo elaboradas, no mundo das telecomunicações e da informática. As relações entre os homens, o trabalho, a própria inteligência dependem, na verdade da metamorfose incessante de dispositivos informacionais de todos os tipos".

O programa de aprendizagem de Química contém somente duas horas semanais práticas, necessitando ser trabalhado por meios ativos. As aulas foram ministradas com auxílio do ambiente de Aprendizagem Colaborativa a Distância via Internet denominado "EUREKA", desenvolvido pela PUCPR e SIEMENS mediante o do Laboratório de Mídias Interativas (LAMI, 1998).

Utilizaram-se quatro procedimentos pedagógicos: a) aula expositiva dialogada com apresentação de vídeo e discussão; b) aula expositiva dialoga- 
da com prática laboratorial; c) aula expositiva dialogada e d) projeto baseado numa pesquisa de campo e apresentado na forma de seminário.

As três primeiras aulas do semestre versaram sobre normas de segurança e técnicas de trabalho no laboratório; na quarta semana foi apresentado um tema mediante um de vídeo, pois se tratava de um assunto abstrato de difícil compreensão. As aulas seguintes foram aulas expositivas dialogadas com prática laboratorial e na penúltima semana do período letivo houve uma aula expositiva dialogada (teórica), a qual não foi possível demonstrar no laboratório de Química, pois precisava-se de um laboratório de eletricidade.

No final do programa de aprendizagem, o projeto realizado teve como objetivo levar os alunos a vivenciarem uma pesquisa de campo, entrevistando profissionais da área para conferir a ligação entre a química e as telecomunicações. A última aula do semestre foi a apresentação do seminário, mostrando os resultados desse projeto.

A partir das contribuições de seis questionários e uma entrevista aplicados em diversos momentos, surgiram propostas de melhorias e transformações no processo de ensino-aprendizagem.

\section{Análise e Discussão dos Resultados}

Os resultados obtidos no questionário que tratou de "Conhecimentos Básicos de Informática" eram esperados; os alunos do curso de Engenharia Elétrica-Telecomunicações não têm dificuldades com as diversas ferramentas da informática e a cada ano que passa observa-se que os estudantes vêm mais preparados para usar o computador. Houve inúmeras informações relevantes para conduzir esta matéria por meio da sondagem sobre a atuação dos mesmos no ensino médio.

Na questão que averiguava a causa de dificuldades no Ensino Médio, foram apontadas várias respostas. Ficou demonstrado que, para o conjunto estudado, a principal deficiência do ensino médio é a aula tradicional de química, onde se estudam inúmeras teorias sem poder constatá-las. Outra possível carência do ensino médio segundo os discentes é a ausência de aulas práticas. Houve 37,50\% de abstenção nesta resposta. Os estudantes não colocaram suas opiniões, talvez por não terem analisado as causas desta deficiência.

Outra questão pedia sugestões para tornar melhor o programa de aprendizagem de Química, cujas respostas estão na tabela a seguir: 
TABELA 1 - Sugestões dos alunos para tornar o programa de aprendizagem de química agradável

\section{SUGESTÕES}

Aulas Práticas relacionadas

com o curso

Aulas ligadas com o cotidiano

Trabalhos de Pesquisa

Uso de Informática

Aulas mais descontraídas

Abstenção
PORCENTAGEM (\%)

57,89

10,53

10,53

10,53

5,26

5,26

O questionário sobre "Conhecimentos Básicos de Química” mostrou que a aplicação de modelos prontos de ensino resolveu para a maioria das respostas, entretanto, no momento em que o conhecimento deveria ser elaborado houve muita abstenção de respostas, assim como respostas erradas.

O conhecimento geral existia, porém as respostas que exigiam mais vocábulos técnicos foram difíceis de ser respondidas.

Após os questionários de "Avaliação de Procedimentos Pedagógicos" e da entrevista, fez-se uma comparação entre os quatro procedimentos pedagógicos adotados, analisando-se as questões que envolviam os seguintes assuntos: motivação, dinâmica e satisfação. Calculou-se a média e, em seguida, a porcentagem que equivaleria esta média.

Uma questão perguntava se a metodologia de ensino usada na aula aumentou a participação ativa destes alunos (motivação); outra questão indagava sobre o uso de metodologias de ensino, dinâmicas, perguntas, conversas, discussões e exercícios (dinâmica) e outra perguntava se o que o discente tinha aprendido com a metodologia adotada correspondia as suas expectativas (satisfação). Os resultados estão no gráfico abaixo: 
GRÁFICO 1 - Resultados das metodologias aplicadas com os alunos

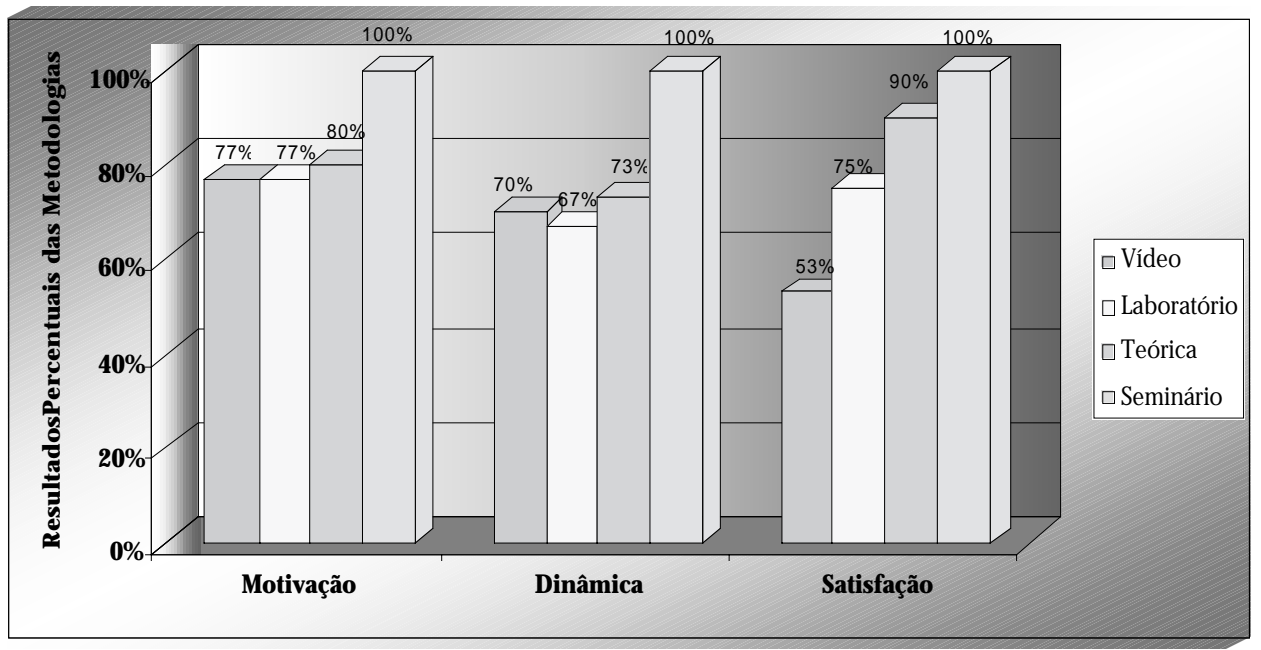

Percebe-se que a motivação em relação à aula de vídeo, laboratorial e teórica ficou muito próxima em termos percentuais; a dinâmica da aula foi aproximadamente $70 \%$ para os dois primeiros procedimentos pedagógicos e um pouco acima para a aula teórica, porém as três metodologias também ficaram percentualmente muito próximas. A aula de vídeo foi relevante no que tange a informações curiosas acerca dos experimentos das teorias atômicas. A aula de laboratório conquistou 75\% de satisfação, mostrando que houve contentamento em relação às práticas, aos materiais e à organização; a aula teórica também satisfez porque tratava de um assunto interessante abordado com dinamismo, atingindo $90 \%$ de contentamento.

O seminário atingiu 100\% em todos os itens analisados e foi o procedimento que mais agradou a todos. Algumas vantagens desta técnica são a socialização ao trabalhar em grupo, a auto-aprendizagem, a troca de experiências, a cooperação, descobrem-se as diferentes situações-problema e há incentivo para pensar de forma independente.

É uma forma de estimular a pesquisa para conhecer o mundo de profissionais de Engenharia Elétrica e impulsionar os discentes a manterem este espírito inquiridor que a sociedade moderna exige.

Analisaram-se os resultados de uma questão que versava sobre a contribuição dos conteúdos abordados na aquisição de novos conhecimentos. Outra questão sondava se os conteúdos enfocados contribuíram para aprofundar os conhecimentos no assunto em estudo. Os resultados foram: 
GRÁFICO 2 - Aquisição de conhecimentos dos alunos

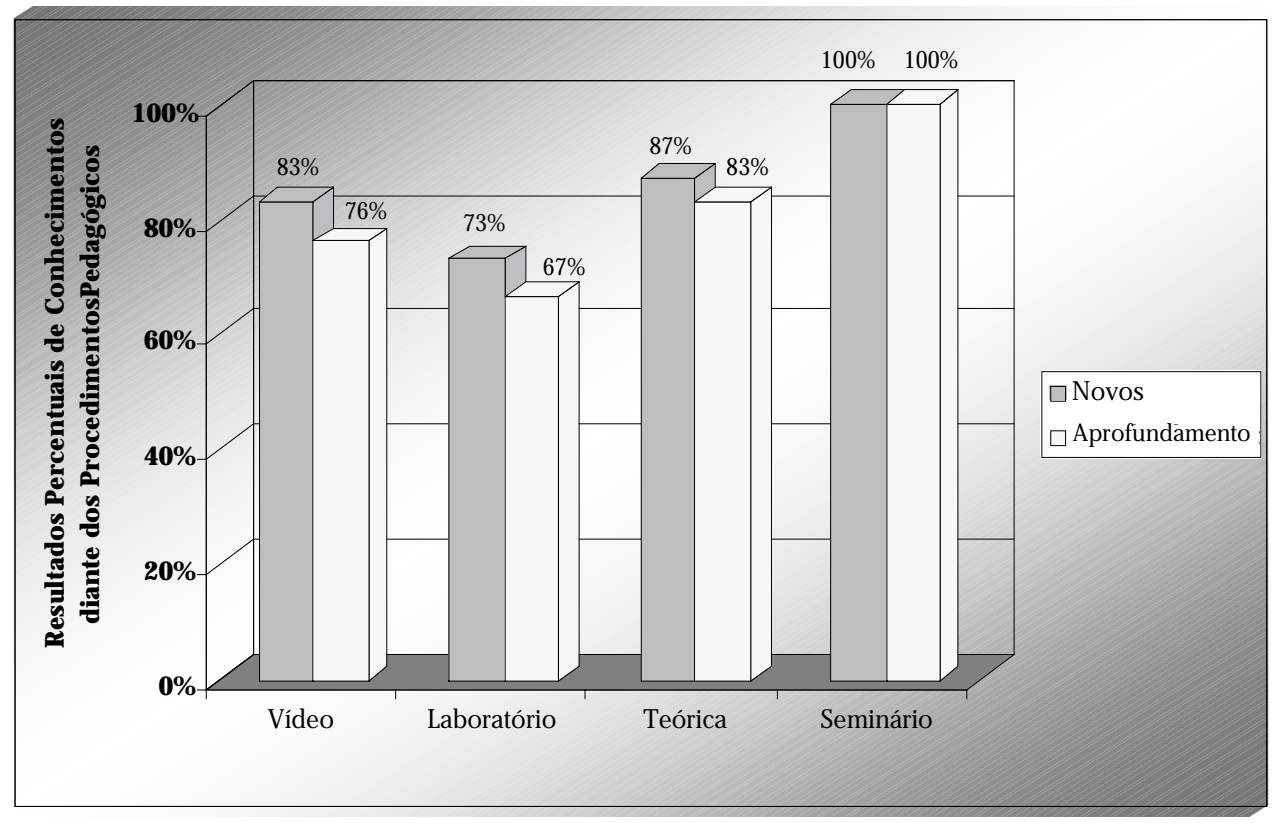

O seminário foi o preferido, levou os alunos à aprendizagem, mediante a construção de conhecimentos. A aula teónica aprofundou informações e certos estudantes conheceram um assunto mais específico de sua área como "Semicondutores"; a aula de laboratório trouxe conhecimentos novos, pois estavam vendo situações diversificadas na prática; no entanto, julgaram que houve um aprofundamento parcial dos conhecimentos porque os assuntos no laboratónio são aprofundados segundo o que o discente já possui de conhecimento de química. $\mathrm{O}$ vídeo para boa parte da turma trouxe conhecimentos novos, tiveram a oportunidade de ver experimentos que só haviam sido comentados em aula teónica.

\section{Conclusão}

A mudança no estudo da química se faz necessária, desde a formação de professores desta matéria, devendo-se priorizar:

- visão mais globalizada dos assuntos a serem estudados;

- aulas mais criativas;

- introdução da evolução histórica desta ciência para entender melhor a evolução de seus conceitos, modelos e objetivos; 
Uma comparação entre estratégias de ensino da química na educação superior

- relação da história desta ciência com a história da própria sociedade em que está inserida, em seus aspectos científicos, sociais e tecnológicos;

- ênfase para o discente da visão contextualizada e crítica que 0 leve à tomada de decisões.

A proposta de fazer um programa de aprendizagem exclusivamente prático, no curso Engenharia Elétrica - Telecomunicações, partiu em princípio de uma redução de carga horária de 4 horas semanais para 2 horas semanais, baseado na grande expectativa dos alunos em relação à aula de laboratónio e nas atitudes críticas em relação à aula teórica. Apenas dois conteúdos foram dados de forma mais teórica, por exigirem uma exposição de maior quantidade de detalhes.

A idéia central era levar o educando a acompanhar teoricamente os assuntos com o apoio do ambiente de aprendizagem colaborativa EUREKA, fundamentando a teoria com a aula prática. Evidentemente que foram realizados relatórios das práticas laboratoriais, exposição de seminário e, em certos pontos da aula prática, havia enfoques teóricos.

Os alunos sentiram-se motivados ao relacionar o que vêem na aula com sua vida no dia-a-dia; os questionários e a entrevista demonstram que o seminário foi o melhor dos procedimentos pedagógicos para contextualizar e dinamizar. Isso se justifica já que foram em busca do assunto por meio de uma pesquisa de campo, na qual conviveram com profissionais da sua futura profissão e puderam ver a realidade do mundo das telecomunicações bem de perto.

A metodologia que gerou mais satisfação foi o seminánio: os alunos se sentiram mais ativos e producentes. Ficou em segundo lugar o método tradicional que apresentou uma aula sobre um conteúdo específico de Engenharia Elétrica; em seguida a aula de laboratório permitiu aos alunos produzirem e aplicarem conhecimentos. Em último lugar foi o vídeo que não causou muita satisfação, visto que muitos se sentiram como meros expectadores por terem dificuldades ou falta de interesse no assunto, apesar de se ter levado à discussão após assistirem ao filme.

A apresentação do vídeo não obteve resultados tão bons porque 0 filme era um documentário, e não criava um "enigma" (MEIRIEU, 1998) para que nascesse o desejo de aprender nos alunos. A estratégia alternativa é o uso de vídeo com "instrução ancorada".

De acordo com Alcantara citando Bransford e pesquisadores (p. 147, 1990):

O conceito de instrução ancorada se refere ao uso de vídeo que serve como uma âncora ou contexto para introduzir informações relevantes ao estudante para a solução de situações problemáticas...Assim a instrução ancorada é um modelo que usa um formato de vídeo gerativo. Um ambiente de vídeo 
expõe situações que fazem com que os estudantes gerem metas e submetas, encontrem informação relevante imbutida no vídeo para solucionar a situação problema. A preferência em usar vídeo gerativo se relaciona com o fato de que a base teórica por trás da instrução ancorada (i.e., posição construtivista) assume que estudantes não podem aprender e desenvolver conhecimentos se as atividades apresentadas o fizerem aprendizes passivos.

Os estudantes precisam produzir e não apenas receber informações. O ser humano se sente gratificado quando vê o produto do seu trabalho gerar frutos, o aluno se satisfaz ao pesquisar assuntos relevantes, instigado pelo professor a obter conhecimentos novos e importantes.

As respostas obtidas no questionário em correlação à satisfação mostraram que os alunos ainda julgam o professor como um ser superior que ensina a ignorantes. É o que chama Freire de "consciência bancária", em que o aluno recebe os conhecimentos de maneira não crítica, tornando-se um depósito do seu professor. No entanto como diz FREIRE (1990, p. 38):

Educa-se para arquivar o que se deposita. Mas o curioso é que o arquivado é o próprio homem, que perde assim seu poder de criar, se faz menos homem é uma peça. $O$ destino do homem deve ser criar e transformar o mundo, sendo sujeito de sua ação. A consciência bancária 'pensa que quanto mais se dá mais se sabe'. Mas a experiência revela que com este mesmo sistema, só se formam indivíduos medíocres porque não há estímulo para criação.

Os estudantes permaneceram passivos recebendo o conhecimento, mas não notaram que assim deixaram inerte o seu espírito crítico, contestador e de análise. É claro que é mais fácil não precisar pensar; o uso de recursos tecnológicos como computador e calculadoras que fazem gráficos, estatísticas e acumulam na memória uma série de informações faz o estudante ficar muito dependente destes tipos de recursos que podem facilitar a vida estudantil se utilizados de outra maneira.

A explicação para a atitude tácita dos discentes perante uma aula tradicional foi por ser a única aula expositiva dialogada no semestre, não permitindo que se cansassem com tal atividade. Existe necessidade de aula teórica para o embasamento em certos assuntos para gerar uma maior produção de conhecimentos.

$\mathrm{Na}$ aula de vídeo exigiu-se mais dos seus conhecimentos prévios o que não agradou muito. Da mesma forma, na aula de laboratório, a informação não vinha pronta, ela deveria ser analisada e explicada.

Quanto à aprendizagem, as respostas do questionário e da entrevista apontaram novamente para o seminário, no qual produziram conheci- 
mento. Os procedimentos, aula com vídeo e aula teórica ficaram praticamente empatados em termos de novos conhecimentos adquiridos, julgando-se pelo resultado uma boa aprendizagem com estas técnicas. De acordo com Bireaud (1995, p. 100), “A maior ou menor eficácia de um determinado produto pedagógico não depende de ser áudio-visual. A eficácia depende da sua leitura e do uso que dele se faz".

Portanto, se o professor sabe instigar os alunos nos pontos importantes de um vídeo e os mostra de forma adequada, a aula não fica cansativa e torna-se interessante. Parece que o resultado em relação ao vídeo foi positivo, porque implicou numa escolha adequada do material áudio-visual, pois cabe ao educador avaliar este material antes de mostrar aos seus educandos, observando as partes importantes, apresentando-o de maneira coerente.

A aprendizagem no laboratório não foi tão alta porque não basta saber o que ocorre microscopicamente se não relacionar com os fenômenos macroscópicos vistos no laboratório e vice-versa.

O seminário foi o procedimento pedagógico preferido, porque obtiveram a verdadeira aprendizagem que é "aquela construída com esforço próprio através de elaboração pessoal” (DEMO, 1990, p. 64). Os alunos tiveram oportunidade de mostrar por meio da exposição do seminário o produto da sua pesquisa, com liberdade de apresentar-se usando os recursos que julgassem necessários, e da maneira mais criativa possível. Tais atitudes geraram um grau de satisfação muito grande a todos, pois eles próprios descobriram como eram criativos.

Os educadores devem refletir de forma constante sobre a sua atuação profissional, e esta sendo diferenciada passa a ser modelo até quem sabe para outros profissionais principalmente da área de Química, onde muito pouco se modifica.

O professor que levar o aluno a refletir, a analisar, a sintetizar, a contextualizar, poderá acordar seu espírito crítico e de pesquisa para que a aprendizagem seja mais significativa.

\section{Referências}

ALCANTARA, P.R. Instrução ancorada baseada em vídeo no desempenho de trabalho de estudantes com necessidades especiais. Revista Brasileira de Educação Especial, v. 6, n.1, p. 147-164, 2000.

BIREAUD, A. Os métodos pedagógico no Ensino Superior. Porto: Porto, 1998. 
DEMO, P. Pesquisa: princípio Científico e Educativo. 2. ed. São Paulo: Cortez, 1990.

FREIRE, P. Educação e Mudança. 16. ed. Rio de Janeiro: Paz e Terra, 1990. LÉVY, P. As Tecnologias da Inteligência. São Paulo: 34, 1995.

MEIRIEU, P. Aprender...Sim, Mas Como? 7. ed. Porto Alegre: Artes Médicas, 1998.

Recebido em: 12/10/02

Aprovado em: 23/11/02 